DOI: https://doi.org/10.47405/mjssh.v6i3.707

\begin{tabular}{|c|c|}
\hline 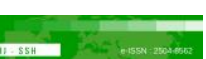 & Malaysian Journal of Social Sciences and Humanities (MJSSH) \\
\hline Malaysian Journal of & Volume 6, Issue 3, March 2021 \\
\hline (MJ-SSH) & e-ISSN : 2504-8562 \\
\hline & $\begin{array}{l}\text { Journal home page: } \\
\text { www.msocialsciences.com }\end{array}$ \\
\hline
\end{tabular}

\title{
Employment of Language Learning Strategies by Chinese School Learners in Learning ESL Vocabulary
}

\author{
Chan Hie Chen 1 , Azlina Abdul Aziz ${ }^{2}$ \\ ${ }^{1}$ Sekolah Jenis Kebangsaan Cina Chung Hua Roban, Daerah Saratok, 95400 Saratok, Sarawak, Malaysia \\ ${ }^{2}$ Faculty of Education, Universiti Kebangsaan Malaysia (UKM), 43600 Bangi, Selangor, Malaysia \\ Correspondence: Chan Hie Chen (hzhen0725@gmail.com)
}

\begin{abstract}
Language Learning Strategies (LLS) are widely implemented in the learning of English as a second language (ESL). In order to make the language communicable, vocabulary is the main element to cope by the ESL learners. Hence, LLS is helpful in aiding the learners to develop the ESL vocabulary effectively according to the learners' needs. Derived from the issue, the study is aiming to identify the best strategies among the Chinese school learners as they share the same environment background in learning ESL vocabulary. A survey was distributed through google form to all the Chinese primary schools in a sub-urban district. The total number of sixty two respondents in Primary Five were chosen in collecting the LLSs in learning ESL vocabulary with the learners' academic achievement. The findings portrayed the learners who performed high academic achievement are those implemented metacognitive strategies widely when learning vocabulary. Thus, the findings could be an alternative for teachers and learners in future teaching and learning of ESL vocabulary in Chinese schools.
\end{abstract}

Keywords: English as a Second Language (ESL), ESL Learners, Language Learning Strategies (LLSs), Chinese Primary Schools, Primary Five learners

\section{Introduction}

Second language learners depend largely on the words to build sentences which are meaningful in order to converse in daily communication. From this, the learners themselves have to understand which strategies work the best on them in order to acquire vocabulary effectively. Hence, language learning strategies (LLS) can be in proper discovery to make the learning successful as there are different strategies to work with the brain autonomy to build blocks of words in among the learners (Saengpakdeejit, 2014). Research in learning strategies, Oxford (1990) defines learning strategies as "specific actions taken by the learner to make learning easier, faster, more enjoyable, more self-directed, more effective and more transferable to new situations." (Oxford, 1990, p. 440). From the point of view of Oxford (1990), the learning strategies will not only aid in language learning itself, but the learners will have the ability to response to the certain circumstances and to accomplish their learning in an appropriate way. Educators will be able to grasp the strategies with the aim of promoting teaching meaningfully. 
Nevertheless, the failure of communication in English Language among the ESL learners is the main concern of the Ministry of Education (MOE) in Malaysia and emanating the improvisation in English Language with the engagement with Common European Framework of Reference (CEFR) in order to form international standards of teaching and learning for ESL learners (Uri \& Abd Aziz, 2018). The key factor of the failure is the limitation of the vocabulary and zero association of the vocabulary with the language skills. These shortcomings unfavorably impacted the learners' achievement in English and consequently caused the low proficiency level for English language. Hence, vocabulary needs to be improved in order to achieve meaningful communication in English Language.

In accordance, LLSs have been essential for facilitating the learners to learn independently and an aspect for the educators to trigger for the teaching and learning process. Hence, the adapted Strategy Inventory for Language Learning Version 7.0 (ESL/EFL) (SILL) Oxford (1990) was studied to identify the significant relationship between the LLSs with the academic achievement in order to comprehend the best in teaching and learning ESL vocabulary for Chinese school learners.

\section{Literature Review}

\section{Language Learning Strategies (LLSs)}

Language Learning Strategies (LLS) concerned on the methods learners engage when learning about the language skills. Nazri, Yunus and Mohamad Nazri (2016) claimed language learning strategies had come out with a lot of studies and it grown dynamically in the past decades in ESL context. This illuminated the importance of language learning strategies to trigger and explore in order to create better learning methodologies in English Language teaching and learning. Nhem (2019) postulated the utilization of varies language learning strategies would perform in different outcomes of second language learning. The statement exhibits the learners who utilize the proper language learning strategies will be successful in learning second language and the learners who implement the inappropriate language learning will produce vice versa outcomes. There were various definitions produced for language learning strategies. Wenden and Rubin (1987) cited in Nhem (2019) defined language learning strategies as any gatherings of activities, steps, plans, schedules or practices utilized by the learners to encourage the way toward acquiring, storing, recovery, and complications of language input. O'Malley and Chamot (1990) explained the language learning strategies is the alternatives engaged by learners to assist the fulfillment, storage, retrieval or usage of information. However, Oxford(1990) emerged the learning strategies which agreed and accepted by most of the language experts due to its specific and comprehensive elements in the strategies. Oxford (1990) defined the language learning strategies as learners utilized the details behavioral actions in order to develop simpler, rapider, more enjoyable, more self-directed, more efficient and more manageable in the their learning. As may be seen, the definitions of language learning strategies have been embedded as the tools and facilitation for language learners to acquire the inputs successfully.

As the language learning strategies have been considered as part of the significant aspects in second language learning, Oxford (1990) issued two categories of her learning 18 strategies; direct learning strategies and indirect learning strategies. In the category of direct learning strategies comprise of memory strategies, cognitive strategies and compensation strategies. While indirect learning strategies consist of metacognitive strategies, affective strategies and social strategies. Oxford also designed an inventory name Strategy Inventory of Language Learning (SILL) which has been reviewed and revised for several times and now a popular standard measure language learning strategies. Lyu and Xu (2019); Nazri et al. (2016) and Tandoc (2019) viewed SILL is a long established measuring tool through field experiments and well received by many linguistic researchers around the world.

In the current study, an adapted SILL performed in order to collect the data regarding the LLSs with the learners' academic achievement. LLSs give an idea for the learners to understand themselves better by inculcating themselves an appropriate learning strategies in coping English vocabulary as this is the most important element to master before develop more language skills. SILL developed a Likert Scale, the 
five points scale with thirty items questionnaire including six types of language learning strategies (memory, cognitive, compensation, metacognitive, social and affective strategies) respectively. Oxford (1990) mentioned that through the sensible learning strategies, the learners can be better at using the right learning strategies. Thus, the current study would be helpful as the learners could benefit and teachers could utilize the appropriate learning strategies as the learning setting would be the same for this context.

\section{Vocabulary Learning in ESL}

Learning vocabulary is one of the vital element to ensure communication could be carried out successfully. However, it is also the biggest obstacles faced by the learners in the ESL learning. The ESL teachers should demonstrate the proper learning strategies in order to relieve the current pressure among the ESL learners. There are varieties of vocabulary learning strategies could be employed by learners such as determination strategies, memory strategies, cognitive strategies, metacognitive strategies, social strategies established throughout the devised taxonomy from Schmitt (1977) cited in Goundar (2019). Nonetheless, Yaacob et al. (2019) highlighted LLSs could be another important tool in acquiring vocabulary as LLSs are the onset of the vocabulary learning strategies. Thus, LLSs can be one of the tools to acquire vocabulary among the ESL learners. According to Oxford (1990) cited in Letchumanan, Muthusamy, Govindasamy and Farashaiyan (2016) vocabulary learning among ESL learners can be categorized into two categories which are the direct strategies (memory, cognitive and compensation) and the indirect strategies (metacognitive, affective and social).

Memory strategies enormously engaged in memorization and consolidate the meaning of the new words in ESL learning. Elekaei, Tabrizi and Chalak (2020) deemed memory strategies are related with the techniques of collecting and repossessing new input. Instances for memory strategies are repetition of the words aloud, self-miming or by spelling the words (Al-Omairi, 2020), relating the words with varies graphic explanation of its meaning, word drawing purposes, relation of antonyms and synonyms, retaining new words in sentences, configuration, rewording the meaning of the words, using semantic and lexical knowledge in learning English vocabulary (Schmitt, 1997; Nematollahi, Behjat and Kargar, 2017). With the utilization of memory strategies, the learners would be easily retrieved the words from background knowledge and derived the meaning. Memory strategies are also aiding in boosting vocabulary learning. Benkhenafou (2015) highlighted the strategies could ensure the development of autonomous learners because the learners would be able to prompt learning through glancing the words and remember them easily as the learners have good memory retention.

Cognitive strategies compromise the process from mental relation to the information input through applying, acquiring, processing, remembering and using the information directly. Goundar (2019) postulated the learners who executed cognitive strategies would be able to guess the words by drawing upon of the prior knowledge and utilizing the linguistic clues and grammatical structures of a sentence to derive the meaning of the word. In order word, cognitive strategies highly implemented guessing strategy due to the processes undergo the mental and link to the background knowledge to progress the meaning. Habok and Magyar (2017) added the high proficient learners would more likely to utilize the cognitive strategies because linking to prior knowledge would be widely implement in the strategies. Ali and Razali (2019) inserted the cognitive strategies included the strategies such as questioning, summarizing, clarifying and predicting. At the same time, the process of assessing self-understanding and directing attention would be undergone in cognitive strategies.

Compensation strategies invoked as the instrument to interpret or develop the new knowledge to aid the learners with limited of zero knowledge of the vocabulary and grammar. (Shakarami, Hajhashemi \& Caltabiano 2017) postulated compensation strategies comprised analyzing part of speech, analyzing affixes and roots, checking for a L1 cognate, analyzing pictures or gestures, guessing from textual context, using a bilingual or monolingual dictionary, using word lists or flash cards. Hence, an intelligent guess is needed to link the basic of the language to learn the words. In another word, vocabulary is not learned isolated but in context. Letchumanan et al., (2016) highlighted the important idea where compensation strategies work as linking to solve limitations. When the learners do not have adequate vocabulary repertoire in the message, the individual could rephrase by using the synonyms or gestures to aid the conversation to be carried out effectively. 
Metacognitive strategies are defined as the actions of aiding focus, organize, plan and assess one's learning (Elekaei et al., 2020). Glass (1976) cited in Nematollahi et.al (2017) claimed metacognitive strategies consist of five basic stages. First, determination of issue and articulate types of evidences to figure out. Secondly, the data will be investigation of the issue and gathered all possible data based on the issue arose. Third, the data gathered would be filtered in order to collect useful and correct data and elimination of the data based on the criteria of the issue arose. Statistical techniques, such as potential outcomes and effect sizes, to resolve and collate different subjects would be the fourth stage. Lastly, the presentation of the findings and reporting the result. Metacognitive strategies defined as motivational strategies in term of passion of the learners in the learning of vocabulary by keeping on track of their progress in acquiring the vocabulary (Ali \& Razali, 2019). In brief, metacognitive strategies would be strongly recommended for autonomous learning as the learners will be responsible on their learning and monitor the learning with the stages suggested.

Affective applied to the thoughts, attitudes and inspiration. The strategies can rapidly engaged the learners when learning vocabulary by emerging high self-esteem into the learning. The higher selfesteem produced through the learning in vocabulary, the more effective words could be acquired throughout the process. Oxford (1990) cited in Letchumanan et al., (2016) mentioned the quality of the learning directly affected by the affective aspect of a learner. With the positive employment of thoughts, behavior and motivation in an individual, the contribution in vocabulary learning would be higher as the learners able to confront and resolve the problems encountered.

Social strategies can be defined as the behaviors of involving others in learning a language (Elekaei et al., 2020). Nematollahi et.al (2017) postulated the examples of the social strategies are alliancing between the more knowledgeable others stimulate active information processing. Abtahi, Graven and Lerman (2017) supported the social interaction between the more knowledgeable others would definitely enhance the learning. With the implementation of social strategies, the learners will be well-prepared into group works and they could adapt themselves well in groups. Instances of social strategies were seeking translation in first language (L1) from educators, synonymizing the new words, inquiring meaning of the new words from classmates, ascertaining meaning of the words through group discussion or group work, discovery the meaning of the words through groups and linking the words through native speakers (Nematollahi et al., 2017).

\section{Perceptions on the Effectiveness in Implementing LLSS}

From the voluminous past related studies, perceptions of implementing LLSs from different researches were nominated in their research and various ideas supported on the usage of language learning strategies. According to Ozturk (2018), the implications of utilizing the LLSs would be learners are employing the strategies successfully and effectively, the development of self-directed, self-regulated, self-determining and autonomous learning in language learning. Thereby, the LLSs mean to be useful and beneficial to create independent learning. Erdogan (2018) emphasized the self-regulation determined by the learners when engaging themselves in language learning strategies resulting in the high proficiency learners. The learners proven there is an existing of momentous difference between the implementation of LLSs. Erdogan (2018) added self-regulation as the main concepts in Bandura's Social Learning Theory which described self-regulation is the self-creation ideas, emotions and behaviours that are organized and regularly adapted to the personal goals. In addition, self-regulation encompasses the cognitive skills, motivational factors instances, self-adequacy, objective directions, anxiety and others.

Ozturk (2018) provided an example of application of metacognitive strategies with the perception, the learners illuminated autonomous learner characteristics in sense of making decisions in learning, containing setting goals, outlining contents and processes, choosing appropriate approaches and techniques, observing the procedure and assessing the result of the learning. This progression had been a clear line learners develop high independent learning by acquiring language learning strategies. In accordance to this subject, teachers and learners are highly recommended in constructing LLSs in acquiring vocabulary in order to produce high self-directed, self-regulated, self-determining and autonomous learning among learners. Regardless of the any particular strategies, social strategies in 
LLSs could rapid emerge the learners in coping the vocabulary because they have high opportunity to utilize the words and comprehend it often (Asyiah, 2017).

Additionally, Alharbi (2015) emphasized language learning could be easily developed through social development due to the learning will be conducted in context and learners would have more opportunities to expose with real-life learning. Thus, the voluminous study on the LLSs provided the various insights in development of language. Ariyani, Rusminto and Setiyadi (2018) asserted by detecting what strategies of the skills success the high achievers, the language teachers can teach the low achievers to utilize the strategies so that the language achievement can be raised. Erdogan (2018) claimed from the findings indicated the significant relationship between the learners' achievement levels and the implementation of language learning strategies. This significant findings develop the teachers to refer to the findings in future English teaching and learning lessons. The learners are hoped to benefit the strategies taught and utilize it in learning the vocabulary.

However, there were some arguments from several past studies on different characteristics of the learners might need to implement different strategies because the learners have different motivation, interest and needs in learning (Ozturk 2018). Furthermore, the learners could come from different family background which would definitely affecting the compliance of the LLSs. The statement can be supported through Koc (2017) because the learning environment could be another key element affecting the learners in accomplishing their performance.

\section{Methodology}

\section{Research Design}

The study was implemented with quantitative research design. A survey questionnaire was conducted in the study to indicate the language learning strategies preferred by the Chinese school learners with the academic achievement by the learners. The survey questionnaire was conducted in a likert scale form and the simple demographic details included to perceive the data on the academic achievement. Hence, a quantitative research design was the best suit on this study to derive the findings.

\section{Research Respondents}

The current study is selecting the population from all the National Type Chinese Vernacular Schools (SJKC) in a sub-urban district in Sarawak, Malaysia which is a total of seventy-four learners, three primary schools in the district. The learners from this sub-urban area are surrounded by Iban and Malay communities whereas the low Chinese community is engaged in the SJKCs. Though through purposive homogenous sampling, only sixty two learners has engaged in the quantitative study based on the table for determining sample size from a given population, Krejcie and Morgan (1970).

\section{Research Instrument}

The research implementation was administered with the survey questionnaire in the likert scale form based on the Strategy Inventory of Language Learning (SILL) (Oxford 1990) (Appendix 1). SILL was adapted and adopted to form inventory for vocabulary learning. This instrument is vital in collecting the quantitative data and analyzing the strategies used by learners with the academic achievement. Likert scale questionnaire consisted of six sections, which are Part A, Part B, Part C, Part D, Part E and Part F, with the total of thirty questions and three questions for obtaining the information of the gender, school and learner's academic achievement. Each sections comprised of five questions with five scales and respondents chose according to what they have done when they start learning vocabulary. The five-point Likert scale is set as 1: Totally Diagree, 2: Disagree, 3: Neutral, 4: Agree, 5: Strongly Agree. Part A was administering on memory strategies, Part $B$ was focusing on cognitive strategies and Part $C$ was about compensation strategies. Moving on to indirect strategies, Part D was focusing on metacognitive 
strategies, Part E was administering on affective strategies and Part F was focusing on the social strategies.

The validity of the questionnaire tested through the face and content validity. The expert lecturer expert lecturer who majoring in teaching English as a second language (TESL) validate the questionnaire and have the experience of teaching for more than 30 years. The items in the questionnaire were viewed and has determined its practicality in the research.

The reliability of the likert scale questionnaire was conducted in the pilot study to figure out the reliability consistency. The piloted likert scale questionnaire was piloted and data were collected with the tabulation of data in SPSS Version 25 to attain the Cronbach's Alpha reliability coefficient. The piloted study in the set of questionnaire, it resulted a good internal consistency with the Cronbach's Alpha score of 0.881 . Vaske et.al (2017) clearly mentioned the excellent indication of a good internal consistency and a reliable set of items must be with the measure of more than or equal to $0.8(\geq 0.8)$. This indication clarified the set of likert scale 30 questionnaire is a reliable source to gauge into one of the domain research instrument to assemble the data for the study by the Primary Five SJKC learners in the sub-urban district when learning vocabulary.

\section{Data Collection Procedure}

Before the data was collected from the respondents, the researcher requested the permission form Education Research Application System 2.0 (eRAS 2.0) to carry out the research. Once the letters received, a letter addressed to respondents involved sent out to notify about the Google Form link to the survey and the survey details through every headmasters and teachers. The google form consisted of thirty questions of strategy inventory for language learning with the adaption and adoption for better learning of vocabulary and the demographic data which included the gender, schools' information and learners' academic achievement had been distributed accordingly to the three schools and achieved the amount of sixty two sample size. The samples answered the questionnaires and submitted through google form with teachers' guidance. This would lighten and ease the collection of the hardcopy of the data and all the data had been generated to the softcopy through google form.

\section{Data Analysis Procedure}

As the research question was developing the relationship between the language learning strategies with the learners' academic achievement in the Chinese schools. Hence, inferential statistic was needed to analyse the data to show the correlation between the strategies with the learners' academic achievement. The Pearson correlational test was applied in SPSS Version 25 to indicate the relationship between the language learning strategies in learning vocabulary with the learners' academic achievement. The researcher obtained the data from the google form from the survey questionnaire. Then, all the strategies were calculated to obtain the average mean in order to bivariate the data. To better analyse the various learning strategies implemented by the Chinese school learners, the researcher used the following magnitude by Schober et. al (2018) to better interpreting the correlation coefficient which significantly relating between LLSs with the learners' academic achievement.

Table 1: Conventional Approach to Interpreting a Correlation Coefficient (Schober et.al, 2018)

\begin{tabular}{cc}
\hline $\begin{array}{c}\text { Absolute Magnitude of the Correlation } \\
\text { Coefficient }\end{array}$ & Interpretation \\
$\pm 0.00- \pm 0.10$ & Negligible correlation \\
$\pm 0.10- \pm 0.39$ & Weak correlation \\
$\pm 0.40- \pm 0.69$ & Moderate correlation \\
$\pm 0.70- \pm 0.89$ & Strong correlation \\
$\pm 0.90- \pm 1.00$ & Very strong correlation \\
\hline
\end{tabular}




\section{Result \& Discussion}

Is there any significant relationship between using various LLS when learning vocabulary with the learners' academic achievement in Chinese schools?

Table 2: Correlation between LLSs and learners' academic achievement

\begin{tabular}{lc}
\hline \multicolumn{1}{c}{ Correlation between LLSs' mean and Learners' Academic Achievement } \\
\hline Memory Strategies & .177 \\
Cognitive Strategies & $.329^{* *}$ \\
Compensation Strategies & $.348^{* *}$ \\
Metacognitive Strategies & $.714^{* *}$ \\
Affective Strategies & .229 \\
Social Strategies & .152 \\
\hline$* * p<01$ &
\end{tabular}

Aforementioned in the study, there were six LLSs, memory strategies, cognitive strategies, compensation strategies, metacognitive strategies, affective strategies and social strategies have been analysed through Pearson's Correlation. In order to indicate whether or not the LLSs when learning vocabulary significantly related with the learners' academic achievement in Chinese schools, the researcher conducted the data analysis with all the strategies' mean learners' academic achievement.

Table 2 above proposed the data with a positive effect on implementing the six strategies above. According to Schober et.al, (2018) a strong correlation between the variables are within \pm 0.70 to \pm 0.89 . Table 2 indicated metacognitive strategies illustrated the highest significant $r$ value, $r=0.714$. Hence, the findings exhibited a strong relationship between the metacognitive strategies with the learners' academic achievement. This shows the respondents who executed the strategies as follow; discovering various ways in using English words, noticing mistakes and utilising the information to improve in future learning, setting up a timetable, setting up clear goals in learning vocabulary and ensuring the progress in learning vocabulary would be able to demonstrate higher scores compared to the other strategies. The strategies above accentuated on the self-discovery in the learning of vocabulary. The study conducted Erdogan (2018) supported the metacognitive strategies tend to be a useful strategies for learners to do self-learning as they do not need to be depending on any other individuals but the self-regulation would rather help the learners to conduct the development of the vocabulary learning in order to achieve the personal goals. Ali and Razali (2019) supported the metacognitive strategies would create motivational strategies in spontaneously which enhance the learners in the learning needs and enthusiasm for the vocabulary learning because they monitored on their progress in learning. At the same time, the learners could build their own self esteem because they could mark their success after each time they have achieved it. Erdogan (2018) postulated from his study and supported the high achievers preferred to implement this strategies because they have high self-regulation in coping the vocabulary. This circumstance demonstrated the respondents show high responsibilities in own learning in order to achieve the goal. Ozturk (2018) supported the study by providing an example of application of metacognitive strategies with the perception, the learners illuminated autonomous learner characteristics in sense of making decisions in learning, containing setting goals, outlining contents and processes, choosing appropriate approaches and techniques, observing the procedure and assessing the result of the learning. In order to develop high independent learning in learning vocabulary, the respondents mostly implementing the above strategies to ensure the effective progression of vocabulary learning. In addition, the high achievers have better learning environment due to the family background. The family could support the learners who utilized metacognitive strategies with proper Internet connection in learning, buying more storybooks for them to read and spending more time in taking care on the learners' learning process. Koc (2017) asserted the learning environment could be another factor affecting the learners in executing their performance. Hence, throughout the current strategies, the teachers could select the appropriate learning materials such as blended learning, home quizzes to aid the learning of the vocabulary and expose the learners with more words in order to comprehend the language. 
On the other hand, Table 2 demonstrated the lowest significant correlation on the social strategies, $\mathrm{r}=$ 0.152 . Schober et. al,(2018) demonstrated the weak correlation coefficient is between \pm 0.10 to \pm 0.39 . From the finding above, it illustrated the social strategies exhibited low significant relationship with the learners' academic achievement. This shows the respondents who engaged with practicing English words with friends, requesting someone to repeat or slow down in uttering the words, asking questions in English, requesting English teachers to correct the wrong usage of words and asking help from friends who are good in English would not be able to perform high achievement compared to other strategies. With the low correlation shown, it deliberates the low achievers would most probably like to use social strategies. Asyiah (2017) postulated the English vocabulary learning through social would be able to ease the learners to practice the language in daily communication. Hence, this strategies prompt to develop language unconsciously but it did not play a significant role in engaging the respondents in develop the English words in order to perform in the examination. According to Alharbi (2015), social development is vital in language development as it develops the language explicitly through acquiring vocabulary in context. However, the data shown the low correlation as the respondents do not develop the vocabulary thoroughly through social strategies due to their socio-economy background. Most of the respondents in the current study have low socio-economy background, thus they do not have sufficient learning materials and approaches to learn the language better. As mentioned by Kubra (2017) learning environment is an important factor to enhance the learning. Though, the respondents who took part in the social strategies would be able to learn from more knowledgeable others such as peers and teachers. Abtahi et al. (2017) asserted the more knowledgeable others act as the tool to enact the learning because the learners could perceive more knowledge through social interaction. As for the current circumstance, the respondents who could not access to more learning materials, they would more likely to implement the social strategies. Therefore, teachers could assist the learners to wisely utilize the strategies in order to acquire more words in English language.

Besides the two strategies discussed, Table 2 also illustrated the data for the memory strategies, cognitive strategies compensation strategies and affective strategies, the r-value illustrated weak correlation with $0.177,0.329,0.348$ and 0.229 respectively. The memory strategies, cognitive strategies, compensation strategies and affective strategies were not widely utilized by the respondents, the correlation above demonstrated the less proficient respondents would mostly likely to employ the above strategies. Habok and Magyar (2017) mentioned the more proficient learners tend to employ on cognitive strategies as it needed more language skills when employing the strategies. Cognitive strategies needed to engage with the information through questioning, summarizing, clarifying and predicting (Ali \& Razali, 2019). Thus, it could be emphasized the correlation above shown the respondents did not have sufficient knowledge and facilitation in employing the above strategies. Benkhenafou (2015) supported the memory strategies in boosting vocabulary learning and develop autonomous learners because they would be able to do the learning by themselves when they want to remember some phrases or words anytime. In contrary, the researcher could not deny that some of the respondents have good memory when learning vocabulary. Even though it was limited correlation between the memory strategies and the learners' academic achievement, this strategies also useful for learners as it could act as a full equipped tools for learners to risen the motivation in learning vocabulary. Compensation strategies have been categorized as one of the analytic techniques as predicting, using gestures, restating (Shakarami et. al, 2017). The following strategies were employed in the survey and the respondents demonstrated weak significant impact between the compensation strategies and learners' academic achievement as well as affective strategies among the Chinese school learners. This would likely because the respondents were inadequate of vocabulary repertoire and could not find the proper word to rephrase the unknown word in the communication. Based on Oxford (1990) cited in Letchumanan et. al (2017), the learners' success or failure in acquiring vocabulary were widely influenced by the affective element. This is because a positive motivation and attitudes towards learning will greatly prompt the learning of vocabulary. Nonetheless, the limited correlation from the respondents illustrated the respondents did not utilize the strategies wisely and facilitation from teachers are greatly needed to fully utilize the strategies in the ESL learning. At the same time, Nhem (2019) highlighted the consequences in second language learning of implementing the language learning strategies would be varies and prompts the language acquisition among ESL learners. In addition, Ariyani et al. (2018) asserted the teachers could reflect on the strategies utilized by the high achievers and risen the academic achievement through the adapted strategies 
implemented by the high achievers. Henceforward, teachers play an important role in developing the strategies among the learners to enhance the learning.

\section{Conclusion}

The study aimed to identify the best language learning strategies in the Chinese schools as there are limited Chinese schools in this area. The findings of study displayed the metacognitive strategies $(\mathrm{r}=0.714)$ correlated rigorously with the learners' academic achievement. This portrayed the learners in the Chinese schools tend to develop vocabulary through self-learning and responsible on the own learning. The findings of study also showed that social strategies $(r=0.152)$ used by the respondents with low correlation in their academic achievement. The weak achievement learners mostly used social strategies when learning vocabulary as they need more help from the more knowledgeable others to assist during the learning. Hence, this paper implies the learning of vocabulary is important to aid the learners and teachers to identify the proper LLSs to be utilized in the future teaching and learning in the Chinese schools as there are only limited Chinese schools in the current sub-urban area. The teaching and learning of vocabulary is the fundamental of the English language. Henceforward, the exposure of LLSs is essential to aid the language learning. The current study is focusing on the learners in Chinese schools who have limited exposure of English language in learning vocabulary with the LLSs. Future studies are recommended to develop each strategies to the learners in learning the other language skills such as listening, speaking, reading and writing as the different learners would make full use of different language strategies in their learning.

\section{References}

Abtahi, Y., Graven, M., \& Lerman, S. (2017). Conceptualising the more knowledgeable other within a multi-directional ZPD. Educational Studies in Mathematics, 96(3), 275-287.

Alharbi, A.M. (2015). Building vocabulary for language learning: approach for ESL learners to study new vocabulary. Journal of International Students, 5(4), 501-511.

Ali, M.A. \& Razali, A.B. (2019). A review of studies on cognitive and metacognitive reading strategies in teaching reading comprehension for ESL/EFLlearners. English Language Teaching, 12(6), 94 111.

Al-Omairi,M. (2020). The use of vocabulary learning strategies by EFL and EAP undergraduate university learners' in the Iraqi context. Arab World English Journal (AWEJ): Special Issue on the English Language in Iraqi Context, 111-120.

Ariyani, F., Rusminto, N. E., \& Setiyadi, A. B. (2018). Language learning strategies based on gender. Theory and Practice in Language Studies, 8(11), 1524.

Asyiah,D.N. (2017). The vocabulary teaching and vocabulary learning: perception, strategies and influences on students' vocabulary mastery. Jurnal Bahasa Lingua Scientia, 9(2), 293-318.

Benkhenafou, H.H. (2015). Memory strategies: boosting vocabulary learning and learner autonomy. International Journal of English and Literature, 5(4), 113-122.

Elekaei, A., Tabrizi, H.H. \& Chalak, A. (2020). A study into the impact of the choice of cognitive and meta-cognitive strategies and podcasts on vocabulary gain and retention levels in the telegrambased e-learning context. Teaching English with Technology, 20(2), 98-117.

Erdogan, T. 2018. The investigation of self-regulation and language learning strategies. Universal Journal of Educational Research, 6(7), 1477-1485.

Goundar, P.R. (2019). Vocabulary learning strategies (VLSs) employed by learners of English as a foreign language (EFL). English Language Teaching, 12(5), 177-189.

Habok, A. \& Magyar, A. (2018). The effect of language learning strategies on proficiency, attitudes and school achivement, Front. Psychol, 8, 2358.

Koç, H. K. (2017). The preferences of in-service elt teachers' language learning strategies in their own language learning process. International Journal of Languages' Education, 5(1), 359-376.

Krejcie, R.V. \& Morgan, D.W. 1970. Determining sample size for research activities. Educational and Psychological Measurement, 30, 607-610. 
Letchumanan, K., Muthusamy, P., Govindasamy,P. \& Farashaiyan, A. (2016). An overview of preferred vocabulary learning strategies by learners. Asian Social Science, 12(10), 174-179.

Lyu, L.Q. \& Xu, Z.Q. (2019). A case study on L2 learning strategies on middle-aged learners. English Language Teaching, 12(3), 214-219.

Nazri, N.M., Yunus, M.M. \& Mohamad Nazri, N.D. (2016). Through the lens of good language learners: what are their strategies? Advances in Language and Literary Studies, 7(1), 195-202.

Nematollahi, B., Behjat, F. \& Kargar, A. (2017). A meta-analysis of vocabulary learning strategies of EFL Learners. English Language Teaching, 10(5), 1-10.

Nhem, D. (2019). Language Learning Strategies: A comparative study of young adolescent Cambodian learners. International Journal of Language and Literary Studies, 1(2), 34-45.

O'Malley, J. M., \& Chamot, A. U. (1990). Learning strategies in second language acquisition. Cambridge University Press.

Oxford, R. (1990). Language learning strategies: What every teacher should know. Boston: Heinle and Heinle.

Ozturk, S. Y. (2018). Use of metacognitive online reading strategies by student teachers of English. European Journal of Foreign Language Teaching, 3(3), 17-32.

Saengpakdeejit, R. (2014). Awareness of vocabulary learning strategies among EFL students in Khon Kaen University. Theory and Practice in Language Studies, 4(6), 1101-1108.

Schober, P., Boer, C., Schwarte, L.A. (2018) Correlation coefficients: appropriate use and interpretation. Anesthesia \& Analgesia, 126(5), 1763-1768.

Shakarami, A., Hajhashemi, K. \& Caltabiano, N.J. (2017). Compensation still matters: language learning strategies in third millennium ESL learners. Online Learning, 21(3), 235-250.

Tandoc, J.P. (2019). Language learning strategies enhancement training through personality development: a training designed for ESL learners. International Journal of Linguistics, Literature and Translation. 2(5), 380-403.

Uri, N.F.M. \& Abd Aziz, M.S. (2018). Implementation of CEFR in Malaysia: teachers' awareness and the challenges. The Southeast Asian Journal of English Language Studies, 24(3), 168-183.

Vaske, J. J., Beaman, J. \& Sponarski, C. C. (2017). Rethinking internal consistency in Cronbach's Alpha. Leisure Sciences, 39(2), 163-173.

Yaacob, A., Shapii, A., Alobaisy, A. S., Al-Rahmi, W. M., Al-Dheleai, Y. M., Yahaya, N., \& Alamri, M. M. (2019). Vocabulary learning strategies through secondary students at Saudi school in Malaysia. SAGE Open, 9(1), 1-12. 